\title{
The Reaction Towards White Collar Crime: When White Collar Crime Matters
}

\author{
Daniel Larsson* and Tage Alalehto
}

Department of Sociology Umeå University, Sweden

\begin{abstract}
In the present article, we analyze socio-demographic profiles regarding wrongful attitudes toward white-collar crime. This is a well-researched area, however where the vast majority of the studies comes from the USA and UK. In this paper we will investigate wrongful attitudes in a different context - Sweden. We will furthermore not only focus on those having a restricted view of white collar crime, but also people with a liberal view, i.e. people who do not consider white collar crime to be seriously wrong. To identify different groups regarding attitudes towards white collar crime we have used Latent Class Analyses, with the result that we can identify four different groups, among which we focus on a large group (containing $35 \%$ of the sample) having the most restricted view of white collar crime, and a small group ( $4.5 \%$ of the sample) having the most liberal view of white collar crime. The socio-demographic profile of people having a restricted view of white collar crime is quite similar to the previous research. The restricted group consists in general of elderly women that infrequently uses Internet. The liberal group is in great extent an opposite group - containing young men regularly using Internet. We conclude that it is the latter group that is of most interest for future research, not the least because it is a group that may be breeding general distrust, which may strain the society's social solidarity and trustfulness.
\end{abstract}

Keywords: White Collar Crime, Public perception, Socio-demographic profiles.

\section{INTRODUCTION}

In the present paper public attitudes toward white collar crime are investigated. This theme dates back to 1949 and begins with the work of Edwin Sutherland. In his early work, Sutherland $(1949,1983)$ emphasized the impact of white collar criminality on individuals, corporations and society as a whole, stating that white collar crime breeds distrust, lowers social morale, and represents an attack on social institutions. For Sutherland (1940), the public's reaction toward white collar crime was generally ambivalent. In fact, Sutherland argued that the public did not perceive white collar crime as a crime at all since it was thought of as 'victimless' in nature. However, even if it was perceived as a crime, the public remained ambivalent due to its non-violent nature (Aubert, 1952; Schrager and Short Jr., 1978).

Since Sutherland's work, there has been growing interest in the public perception of white collar crime, starting with the major work by Sellin and Wolfgang (1964) on rating the seriousness of crime in general. Research to date has been rather impressive, although the majority and the most influential of this work has been American or British-implying an Anglo-Saxon context. It is not certain, however, that results from an Anglo-Saxon perspective are valid in other contexts. In the present paper the context is Sweden, which differs in many ways from the Anglo-Saxon context. These cultural differences include, among other things, a high

*Address correspondence to this author at the Department of Sociology Umeå University, Sweden; Tel: 46907865197; Fax: 46907866694;

E-mail: daniel.larsson@soc.umu.se level of trust of the public in its fellow citizens ${ }^{1}$ (Rothstein and Uslaner, 2005; Delhey and Newton, 2005) and high taxes, especially regarding personal taxes (OECD, 2006). Sweden is furthermore often depicted as the prime example of a social democratic welfare state regime, characterized by, among other things, low levels of socio-economic inequality (Esping-Andersen, 1990), while the USA has one of the highest levels of socio-economic inequality among the OECD-countries ${ }^{2}$, and the UK is far more unequal than Sweden (OECD, 2011). Furthermore, most previous research has conducted comparisons between street crime and white collar crime, in which respondents have been asked to respond to scenarios that relate to one of the two types of crime (Holtfreter et al., 2008; Schoepfer et al., 2007). Other research has focused on the punitive action of crime (Cullen et al., 2009; Unnever et al., 2008; Almond, 2008). In the present paper the focus lies on another dimension of public attitudes - solely investigating attitudes toward white collar crime itself, but not related to other kinds of crime, scenarios or punitive action.

A third contribution is related to the fact that, in previous research, crime types' particularity has been investigated. In the present paper we will investigate wrongful attitudes regarding three crime types by measuring underlying structures in the data with help of Latent Class Analysis (LCA). This method will not only give a more robust measurement of

${ }^{1}$ People with higher trust in their fellow citizen also in general tend to have for example a positive view of the democratic institutions.

${ }^{2}$ The organization for Economic Co-operation and Development (OECD) is an international economic organization consisting of 34 countries. For more information see OECD.org 
restricted attitudes towards white collar crime (i.e. considering white collar crime as seriously wrong), but also allow the investigation of different attitudes towards white collar crime, including liberal attitudes (if the data contains such an attitude). This was the attitude Sutherland despised, and to great extent used as a motivational factor regarding his work on white collar crime. This last aspect has, to our knowledge, not been investigated yet, even in an Anglo-Saxon context. We argue that this perspective is of interest. Most people probably consider all kinds of crime to be wrong in some sense (otherwise the cohesion in society would be in danger). Most people who do not consider crime, in general, to be wrong most likely can be considered as more abnormal than people who do consider crime as wrong since this opinion most likely occurs less.

The three types of white collar crime we had the possibility to investigate were (due to data restrictions) ${ }^{3}$ : insurance fraud, VAT fraud (value added tax is a purchase tax for the consumer and a sales tax for the seller), and bribery. The perception of white collar crime was examined among different socio-demographic groups. The aim was to investigate distinct socio-demographic profiles regarding different attitudes towards white collar crime. The data used in the present paper was gathered from the European Social Survey (ESS), Round 2, collected in 2004, and is valid for Sweden.

Investigating the socio-demographic profile of wrongfulness in regards to white collar crime is important for at least two reasons. First, the public perception of criminal activities is an indicator of the sense of justice in society (Burton, Karlinsky, and Blanthorne, 2005; Rosenmerkel, 2001; Serajzadeh, 2008; Stylianou, 2003). Second, white collar crime strains a society's social solidarity and willingness to trust others (Shapiro, 1990; Shover and Hunter, 2010), as it may lead to vicious circles regarding, for example, tax violations and corruption. This aspect is especially important in Sweden, which is a high-tax welfare society with relatively high levels of income distribution (Lindgren, 2002).

\section{THE CONCEPT OF WRONGFULNESS}

The literature has presented discussions and debates regarding different concepts that, in one way or another, have measured attitudes towards white collar crime. Most often, the discussion has dealt with the distinction between seriousness, wrongfulness, and harmfulness (e.g., Evans et al., 1995; Rosenmerkel, 2001). Wrongfulness has been related to the morality of committing a crime, while harmfulness has been related to whether the crime committed constituted a problem and how serious such a problem was considered to be. If the wrongful act was harmful, then the wrongfulness was considered to be serious. Regarding the relationship between the three concepts, Rosenmerkel (2001:314) wrote,

\footnotetext{
${ }^{3}$ In this article, Edelhertz's definition of white collar crime is used. Edelhertz (1970) defined white collar crime as 'an illegal act or series of illegal acts committed by non-physical means and by concealment or guile to obtain money or property, to avoid the payment or loss of money or property, or to obtain business or personal advantage'. Edelhertz's definition refers to concealed criminal acts rather than exclusive social ones, which means that the types of white collar crime following from the definition do not have to be business or upper-class-related to be included in this category. It is the nature of the criminal act (concealment and guile) that defines its character.
}

"In terms of white collar crimes, the author would postulate that individuals will rate white collar crimes as wrongful as most other crimes but less harmful than most other crimes, thus creating an overall lower rating in terms of seriousness" - $\mathrm{a}$ hypothesis that was also confirmed in the study (p. 323).

Thus, harmfulness is the link between wrongfulness and seriousness-in other words, the link between a moral status and the extent of that status (see Warr, 1989:819). In the present paper we were able to measure both wrongfulness and seriousness, although not the link to consequences (i.e., harmfulness). As a consequence, we will not discuss harmfulness as a concept, only wrongfulness.

\section{PREVIOUS RESEARCH ${ }^{4}$}

In general, previous research has found differences between socio-demographic groups. Levi and Jones (1985) found that the elderly consider white collar crime more serious (i.e., those who commit that type of crime deserve to be punished) than young and middle-aged people. Levi and Jones used a data set containing 960 respondents from the public and 368 respondents who were police officers in both a northern and a southern location in England and Wales (the exact location was not specified). The response rate for the study was 69.9 percent for the public and 98 percent for the police officers, and was performed by the commission of Research of Marketing, Ltd. The same results were found by O'Connell and Whelan (1996), whose sample was collected by a postal survey with two reminders to a random sample of 1,000 individuals chosen from the electoral register of 1992 in Dublin. Their response rate was 64.8 percent with a satisfying distribution of demographic data between the sample and the population of Dublin, although with some small under- and overrepresentation in age-ranges. Other recent findings, as the National White Collar Crime Center (2006) has revealed, are that those who are female, non-white, not highly educated, and who use the Internet infrequently (if at all) consider white collar crime not only to be wrong, but seriously wrong. The study, performed by the National White Collar Crime Center, consisted of 1,605 respondents (no response rate was reported) from all over the USA. It was randomly sampled by US telephone numbers and collected by telephone questionnaires through the Center for Survey Research at the University of Virginia by a trained staff of interviewers who were specialized in survey research. A few problems encountered during this survey collection were due to two hurricanes, which caused some technical problems. The demographics of the sample were representative of the US population.

Although they are few, studies conducted in other contexts do exist. Non-Anglo-Saxon studies that may be of more

\footnotetext{
${ }^{4}$ In previous research a complex variation of concepts regarding white collar crime has been used. Some studies have used wrongfulness while others have used badness, severity and seriousness. There are differences in the content of these concepts. However, there is not always clear consistency in research between the meanings of these concepts in relation to other concepts (see Warr, 1989). So as not to confuse the reader, we will use two rather distinct concepts-wrongfulness and seriousness-throughout the entire article. Harmfulness is another concept related to the subject investigated in the present paper. Unfortunately, the data used does not allow research on the harmfulness of white collar crime.
} 
importance include an Iranian study based on Iranian students (Serajzadeh, 2008) that found no significant differences between men and women. In some Anglo-Saxon studies the same result has been found, such as in O'Connell and Whelan (1996). On the other hand, in the Iranian study, the significant effects were due to devoutness to one's religion, liberal attitudes, and intellectual tolerance for modernity. The author argues that liberal attitudes in Iran and other Muslim countries correlate with intellectual tolerance of others and being less severe in perception of different crimes, including white collar crime, than traditional and fundamentalist Muslims. The Iranian study had a randomized sample of 1,522 students (no response rate was reported) selected from 20 universities around Iran. The sample had an overrepresentation of males (57.4 \%) and singles (87.3\%). The questionnaire consisted of 24 acts of the dependent variable 'perceived seriousness of crime' in which the respondents were expected to score from 1 to 20 (with 1 meaning minor offense or no offense at all). A total index was then constructed to measure the perceived seriousness of crime by seven categories in which almost every one (except one) of the categories scored satisfyingly in alpha coefficients (between .77 to .92). Bivariate correlation (Pearson's coefficient) and regression analysis was then used to analyze the data.

In a Turkish-American study (Sever and Roth, 2012), traditional crimes were perceived as slightly more serious than white collar crime in Turkey, while in the US, white collar crime is rated as equal or more serious than traditional crimes. This result was explained with the Turkish population's lack of exposure to white collar crime, either in the media or in the form of recent corporate scandals. In the US, on the other hand, white collar crimes and corporate scandals are to a greater extent exposed in media, discussed in the public, and most likely will remain in the spotlight for a long time. The Turkish-American study had a randomized sample of 1,144 Turkish citizens (All above 18 years old; no response rate was reported) collected by a national household survey covering all of Turkey. The survey was collected by face-to-face interviews consisting of 33 questions originally created and used by the national White Collar Crime Center 2005, with small cultural modifications and additions of the questions adapted to fit the Turkish culture (for example 'bar' was replaced by 'tea house'), but no modifications were made regarding context of the questions. In the Turkish sample, the respondents were asked to rate their perception of how serious they believed some white collar and street crime would be through examining 13 crime scenarios and rating them from 1 to 5 (were 1 being not serious to 5 being very serious). The data was analyzed by stepwise multiple regression.

These two examples fully or partially contradict most of the results found in Anglo-Saxon studies, and indicate the relevance of context for the outcome of morality. Context influences the level of legitimacy of some things in relation to other things, such as different types of criminal activity in relation to institutions, which in turn is related to the average level of trust among the people in the society. The legitimacy of the tax system, for example, and people's trust in the system could plausibly influence opinions in society regarding tax crimes. It is furthermore understood that this level of trust is far higher in Sweden (Wilkinson and Picket, 2009;
Rothstein and Uslander 2005) and that the institutional settings, for example, those regarding the tax system, are different in Sweden than in the Anglo-Saxon countries (EspingAndersen, 1990, 1999). With the research done in other contexts in mind, we assume that the Swedish context may make a difference. Also we can ascertain that the sociodemographic profile will be different, an assumption we can make with the support of the fact that the few studies performed in other contexts than the Anglo-Saxon indicate that the institutional context is of importance.

\section{DATA}

The data used in the present paper are valid for Sweden and come from the European Social Survey (ESS), Round 2 collected in 2004 (ESS, 2004) $^{5}$. The original sample was sent to 2,980 people with 1,948 respondents answering the survey, giving us a response rate of $65.4 \%$. The ESS is an academically-driven social survey established in 2001, repeatedly conducted every second year, and is well-known and used regarding investigation about attitudes and trust towards different kinds of institutions in the society. It consists of core modules and rotating modules every time the survey is conducted. We used Round 2, collected in 2004 for our study. In 2004 one of the rotating modules contained questions about the moral economy inspired from a proposal by a team led by Susanne Karstedt at the Department of Criminology in Keele University in the UK. The questions used regarding attitudes towards white collar crime are from this module. The socio-demographic information comes from core questions.

In the data that was used there was a limited number of white collar crimes available that also had corresponding information regarding attitudes. As such, we were forced to limit our analyses to insurance fraud, VAT fraud, and bribery, which are dependent variables in the present paper. This is, of course, a draw back in the study.

\section{THE INDEPENDENT VARIABLES}

The independent variables are constructed from the question 'How wrong, if at all, do you consider the following crimes to be?' using the following answers: Not wrong at all, A bit wrong, Wrong, and Seriously wrong. In general there are few respondents who answered that all of the crimes were Not wrong at all. To deal with this data skew we have merged the categories Not wrong at all and A bit wrong.

To construct a measurement that can investigate the total impact of these three crime types we used Latent Class Analysis (LCA). This type of analysis identifies clusters (or latent classes) that create patterns of relationships between the variables. It can be said that the clusters group people together who share common characteristics regarding the input variables with the principle to classify people based on the probability of belonging to different clusters (Magidson and Vermunt 2001, Hagenaars and McCutcheon 2002). One of the points of LCA is to locate indirect latent factors and use these as variables in analyses. Thus, with this method we

${ }^{5}$ For more information see http://www.europeansocialsurvey.org/ 
Table 1. Attitudes Towards White Collar Crime. Model Fit for Latent Class Analyses

\begin{tabular}{|l|c|c|c|}
\hline \multicolumn{1}{|c|}{ Model } & $\mathbf{L}^{2}$ & BIC(L) & df \\
\hline \hline 1-Cluster & 675,8711 & 524,7739 & 20 \\
\hline 2-Cluster & 162,8237 & 41,946 & 16 \\
\hline 3-Cluster & 100,1673 & 9,509 & 12 \\
\hline 4-Cluster & 52,6293 & $-7,8096$ & 8 \\
\hline 5-Cluster & 36,938 & 6,7186 & 4 \\
\hline
\end{tabular}

investigated if it was possible to discern different categories of attitudes regarding these three crime categories, which could then be related to socio-demographic characteristics.

In Table 1 the model fit for the LCA is presented. As can be seen, four clusters could be discerned. The $\mathrm{BIC}\left(\mathrm{L}^{2}\right)^{6}$ stops to decrease after four clusters are constructed - implying the best possible complexity in the model in relation to the reduction of the degree of freedom in the model. In other words the results are based on the most possible information balanced towards least possible noise/complexity (see Linzer and Lewis, 2011). In Table 2 the outcome of the clusters are presented. We found Clusters 2 and 4 to be the most interesting since these clusters represent the extreme; the second cluster indicates a restricted view of the crime types (high probabilities to answer seriously wrong) and the fourth cluster indicates a liberal view (high probability to answer not wrong/a bit wrong). Furthermore, by using the extreme clusters, which show homogenous results regarding the crime types, we also overcame the problem of only having three crime types. By having such a homogenous attitude towards these types of white collar crime, it may be reasonable to assume that the respondents also could have the same attitudes regarding other kinds of white collar crime types. However, since no previous research has, as far as we know, tested such a hypothesis, it can still be the case that the extreme groups found here could have had other attitudes towards other white collar crime types than we have had the possibility to investigate due to the data restriction.

The first cluster was the largest, containing $43 \%$ of the population, indicating a middle variant of Clusters 2 and 4 (not restricted, nor liberal). The third cluster was quite similar to the second (i.e., high probability to answer seriously wrong), but with the exception of VAT-crime, with a probability of $84 \%$ to answer not wrong at all/a bit wrong.

In the following calculations we used the extremes (Clusters 2 and 4 - the restricted cluster and the liberal cluster), and investigated the probability of the clusters to occur dependent on different socio-demographic indicators. Every respondent in the data had a value on the cluster variables stretching from 0 to 1 , which indicated the probability to belong to each of the clusters. Having the value of 0.84 on Cluster 2 thus indicated that the probability to belong to Cluster 2 is $84 \%$. Since previous research indicated that wrongfulness correlates with people who are elderly, female, belonging to an ethnic minority and who do not frequently

${ }^{6}$ The Bayesian information criterion based on the likelihood-ratio statistic (L2), use the Internet, the assumption is that these sociodemographic characteristics will correlate to the second cluster. Since no research (as far as we know) has been performed regarding people having liberal attitudes towards white collar crime, we have no assumptions about Cluster 4.

\section{THE SOCIO-DEMOGRAPHIC GROUPS ${ }^{7}$}

To investigate the impact of socio-demographic profiles we have used the variables that previous research has shown to be of importance: gender, age, education, use of the Internet, and whether or not one belongs to an ethnic minority (see the section Previous research). Ethnic minority may be understood as a proxy in relation to previous studies (mainly from the USA), which have found that non-white people consider white collar crime as a more serious problem than white people. However, there is no clear distinction between white and non-white in Sweden, as there is in the USA, and the ethnic minority groups in Sweden have a different character than the non-white population in the USA. For example, Sweden is a new immigrant country, while the USA is an old one, and while the ethnic minority groups in Sweden mostly consists of immigrants, this is far from the case in the USA regarding African-Americans and Hispanics (Dahlström 2007). On the other hand, ethnic minority groups in Sweden are in general overrepresented among those who are unemployed, have lower incomes, are to a greater extent poor and socially excluded, and, in general terms, are discriminated against in different ways (Bask, 2008; Gustafsson and Pedersen, 2005; Jonsson, 1995). These are characteristics non-white people (broadly speaking) in the USA share (see for example Goldsmith and Blakely 2010).

Whether respondents belong to a minority group in Sweden has been measured with the question 'Do you belong to a minority ethnic group in Sweden?' with the answer alternatives being Yes or No. How often respondents use the Internet has been measured with the question 'How often do you use the Internet, the World Wide Web or e-mail-whether at home or at work-for your personal use?' with the answers distinguishing between Less than once a week, Once a week, Several times a week, and Every day. The level of education was distinguished between Low education (not finished elementary school, elementary school, lower secondary, and vocational school), middle education (Second year of high school, Third to fourth year of high school, Vocational high

\footnotetext{
${ }^{7} \mathrm{~A}$ similar kind of analysis is made by O'Connell and Whelan (1996) in their concept of 'individual impact', which indicates the victim's beliefs behind the harmful attitudes.
} 
Table 2. Probability Indicator for Attitudes Towards White Collar Crime

\begin{tabular}{|c|c|c|c|c|}
\hline & Cluster1 & Cluster2 & Cluster3 & Cluster4 \\
\hline Wrong & 0,6555 & 0,0237 & 0,0942 & 0,1893 \\
\hline Seriously wrong & 0,324 & 0,9763 & 0,9057 & 0,0007 \\
\hline \multicolumn{5}{|l|}{ Bribery } \\
\hline Not wrong at all/A bit wrong & 0,0597 & 0 & 0 & 0,074 \\
\hline Wrong & 0,4802 & 0,01 & 0,0032 & 0,5091 \\
\hline Seriously wrong & 0,4601 & 0,99 & 0,9968 & 0,4169 \\
\hline Not wrong at all/A bit wrong & 0,4183 & 0,0293 & 0,84 & 0,9162 \\
\hline Wrong & 0,516 & 0,402 & 0,157 & 0,0831 \\
\hline Seriously wrong & 0,0657 & 0,5687 & 0,003 & 0,0008 \\
\hline Mean & 0,6474 & 1,5394 & 0,1631 & 0,0846 \\
\hline Cluster Size & 0,4277 & 0,3528 & 0,1753 & 0,0441 \\
\hline
\end{tabular}

school prior to 1992, Theoretical high school after 1992, University with no degree), and high education (University degree less than 3 years, University degree more than 3 years).

Since previous research has shown that the elderly to the greatest extent consider white collar crime to be seriously wrong, the age variable has been rescaled, which originally was a continuous variable. The reason this was done is to have the possibility to investigate the elderly, and it was not obvious that age correlated in a linear way.

\section{RESULTS}

In Table $\mathbf{3}$ we have employed binary linear regressions with Cluster 2 as the dependent variable in one column, and in the other column Cluster 4. As can be seen, Cluster 2 contains women and predominantly older people in general, especially people older than 50 years. Those belonging to Cluster 2 do not have the highest level of education nor the lowest - but seems to consist of those who have attained the mid-education level. Table $\mathbf{3}$ furthermore shows that Cluster 2 contains people who do not regularly use the Internet. Ethnicity does not seem to matter, since ethnic minorities do not have statistically significantly higher values on Cluster 2 than ethnic majorities. In Table 2 we can also see that those who belong to Cluster 4 tend to be male, young, usually using the Internet and with education level at the mid-level. However, as with Cluster 2, there are no differences between ethnic minorities and ethnic majorities.

From these results we can relatively well confirm the Anglo-Saxon studies showing that it is elderly women who do not use the Internet on a regular basis that consider whitecollar crime to be seriously wrong. However, the results also indicate that in the Swedish context it is not the lowest educated, but those with a mid-level education that consider white collar crime to be seriously wrong. We could furthermore find no differences between ethnic minorities and ethnic majority in our study, while previous research has found differences between non-white and white Americans in the USA.

Those respondents who had a liberal view on white collar crime (i.e. people who do not in any greater extent considers white collar crime to be wrong), had an opposite sociodemographic profile compared with those having a restricted attitude towards white collar crime. They are male, predominantly young and regularly use the Internet. Interestingly enough, there does not seem to be any difference between those who consider white collar crime to be seriously wrong from those who do not consider these crimes as wrong regarding education (both have a mid-level education), and ethnicity does not seem to matter at all regarding attitudes towards white collar crime.

\section{MULTIVARIATE ANALYSES}

It may be the case that some of the significant correlations in Table $\mathbf{3}$ are dependent on other variables. For example, it may be the case that those who belong to Cluster 2 do not use the Internet regularly because they are older than 50 years, and that the Internet may be quite seldom used among these people, and the same could be said regarding Cluster 4 . To take these kinds of deductions into consideration, we 
Table 3. OLS - Bivariate Analyses of the Socio-demography of the Clusters

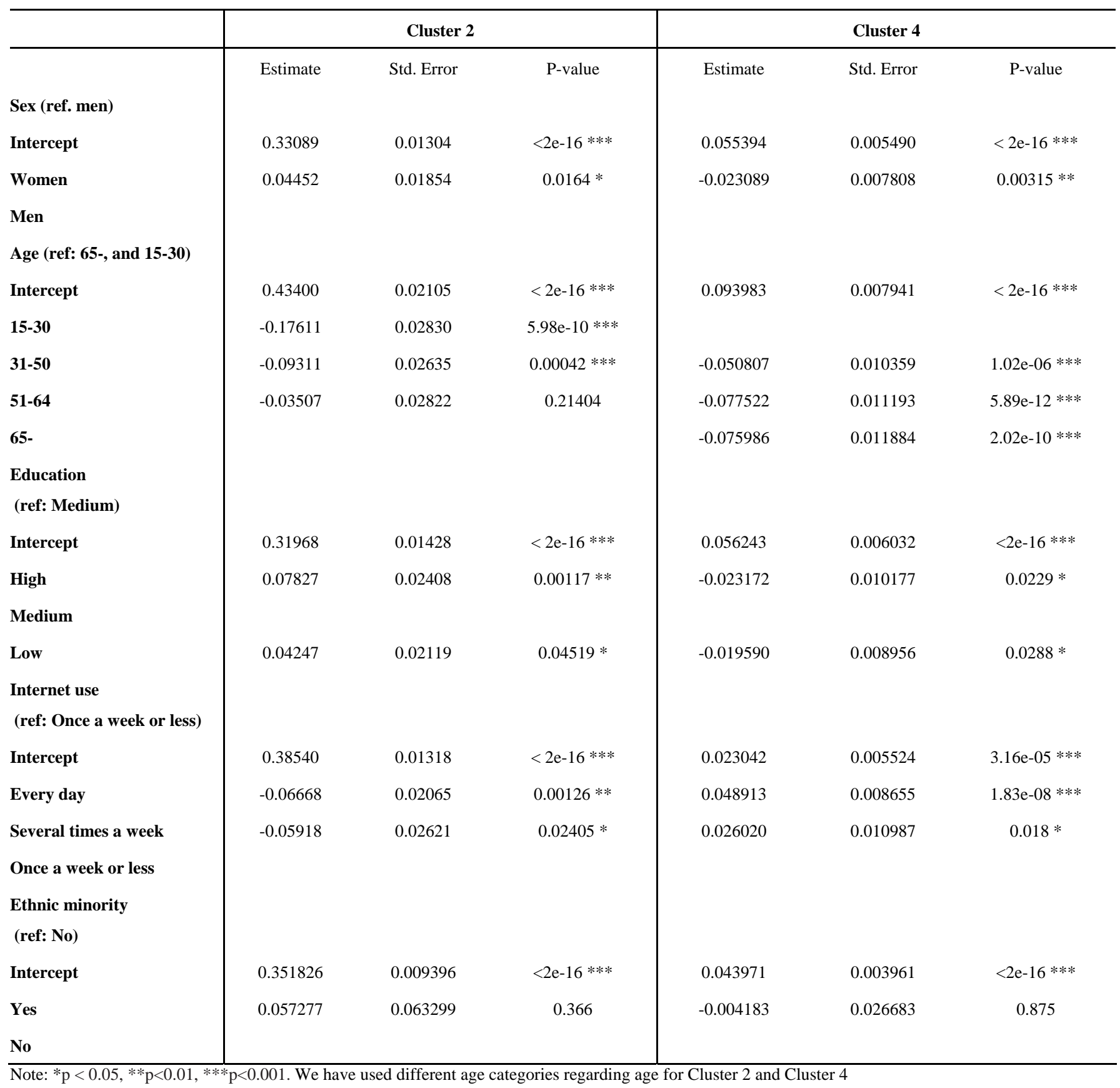

have employed the multivariate analyses presented in Table 4.

In the multivariate analyses, it is only age that matters in the sense that the elderly people (51 and older) in the sample tend to belong to the Cluster 2. Thus, in the multivariate analyses sex, education and Internet use are no longer statistically significantly-related to Cluster 2. Since Cluster 2 is characterized by people who consider white collar crime to be seriously wrong, the analyses performed in Table $\mathbf{4}$ indicate that a homogenous attitude related to all three crimes investigated in the present paper are only related to age, not any of the other socio-demographic characteristics which previous research has shown to be of importance in the An-
glo-Saxon context. On the other hand it can be seen that Cluster 4, the cluster that may be defined as liberal towards white-collar crime, contains substantially more statisticallysignificant results. The people having these liberal attitudes towards white collar crime are young, male and use the Internet substantially more than average.

\section{DISCUSSION}

In the present paper we have investigated attitudes towards white collar crime, with the aim to investigate sociodemographic profiles in a different context (in this case, Sweden) since most other research has been conducted in the USA and the UK. We furthermore did not only investigate those with restricted views (defined as considering white 
Table 4. OLS - Multivariate Analyses of the Socio-demography of the Clusters

\begin{tabular}{|c|c|c|c|c|c|c|}
\hline & \multicolumn{3}{|c|}{ Cluster 2} & \multicolumn{3}{|c|}{ Cluster 4} \\
\hline Intercept & 0.422096 & 0.030198 & $<2 \mathrm{e}-16 * * *$ & 0.085467 & 0.012318 & $5.43 e-12 * * *$ \\
\hline $\begin{array}{l}\text { Sex } \\
\text { (ref: Men) }\end{array}$ & & & & & & \\
\hline \multicolumn{7}{|l|}{ Men } \\
\hline \multicolumn{7}{|c|}{ Age (ref: 65-, and 15-30) } \\
\hline $15-30$ & -0.180109 & 0.033363 & 7.57e-08 *** & & & \\
\hline $31-50$ & -0.105612 & 0.030913 & $0.000648 * * *$ & -0.044228 & 0.010700 & $3.73 \mathrm{e}-05 * * *$ \\
\hline \multicolumn{7}{|l|}{$\begin{array}{l}\text { Education } \\
\text { (ref: Medium) }\end{array}$} \\
\hline High & 0.047625 & 0.024555 & 0.052583 & -0.011611 & 0.010321 & 0.26074 \\
\hline \multicolumn{7}{|l|}{ Medium } \\
\hline Low & -0.014806 & 0.023833 & 0.534510 & 0.003175 & 0.010018 & 0.75136 \\
\hline \multicolumn{7}{|c|}{$\begin{array}{l}\text { Internet use } \\
\text { (ref: Once a week or less) }\end{array}$} \\
\hline Every day & -0.006516 & 0.023982 & 0.785870 & 0.026829 & 0.010081 & $0.00785 * *$ \\
\hline Several times a week & -0.020236 & 0.027553 & 0.462779 & 0.013653 & 0.011582 & 0.23860 \\
\hline
\end{tabular}

collar crime as seriously wrong), but also people that have liberal views (defined as considering white collar crime as not wrong or just a little bit wrong).

The results we found regarding Cluster 2 (the restricted view) are in line with the results found in different studies in the USA and the UK - it is generally elderly women who do not use the Internet that consider white collar crime as seriously wrong. However, there are some deviations too. In Sweden it is not those with the lowest educational level who consider white collar crime to be seriously wrong, but those with a mid-education level. It is, of course, hard to explain this difference, but one important piece of the puzzle may be that the general equality found in Sweden implies that an aspect related to inequality (which the level of education is) has a lower impact. This reasoning is supported by recent research showing that in-work poverty (poverty amongst those who are employed) is less related to one's education level in Sweden than in other European countries (Goerne 2011).
The findings did not indicate that ethnic minorities consider white collar crime as 'seriously wrong' to a greater extent than the ethnic majority. One of the main problems with this variable is that in the USA it is not ethnic minorities that are in focus, but racial differences between nonwhites and whites. Thus, the reason we did not find any differences may be that we are measuring, at least to some extent, something different than what is usually measured in the studies coming from the USA. It is probably furthermore the case that the social relation measured when using the race variable in the USA does not exist in Sweden. In any case, due to the problem in the proxy we used, we argue that the issue of race still needs further research in Sweden (if possible to investigate at all).

It is of some importance to contrast the result we found not only with the common studies performed in the USA and the UK, but also the studies performed on other contexts. The Iranian and the Turkish studies indicate even stronger deviance from USA and UK than we have found in a Swed- 
ish context. Maybe the specific context is not so much the US context or the Anglo-Saxon context, but a Western context. This suspicion calls for more country comparative studies that include both Western and non-Western countries.

In the multivariate analyses (regarding Cluster 2) the only significant result was age. This result implies that Internet use, as we assumed, is related to age (elderly people use the Internet less frequently), and does not by itself correlate to wrongfulness. Furthermore, the gender effect was too weak to be significant when other explanatory factors were involved in the analysis.

In this study we also extended the research area by including those having a liberal attitude towards white collar crime (defined as a high probability to consider the three types of white collar crime as Not wrong/A bit wrong). Interestingly, the socio-demographic profile among this group is opposite to those having a restricted attitude. In general they are younger males who use the Internet frequently. As with the people who had restricted attitudes, this group also generally had a medium level of education, and there are no differences between those belonging to an ethnic minority and those belonging to the ethnic majority. In the multivariate analyses, more variables correlated in a statistically significant way regarding cluster 4 compared with cluster 2 . The reason why these variables hold regarding the people having liberal attitudes, while not for those holding a restricted attitude, may be because the former group is small (constituting $4.5 \%$ ) and more extreme than the latter, and therefore can be considered abnormal; the former, however, constituting about $35 \%$ of the sample, most probably are quite common as these have a more wide spread sociodemographic profile.

This is furthermore a theoretically interesting group. The attitudes they hold indicate an 'attitudinal lack of bond' with the surrounding community. As such, it is our opinion that this specific group may in the future be analyzed from some kind of social bond theory (Hirschi, 1969), specifically one that takes age into account, since age seems to be the dynamic factor that turns the attitude from liberal into restrictive. What we have especially in mind here is the age-grade theory developed by Sampson and Laub (Sampson and Laub, 1993; Laub and Sampson, 2003) who show how the social ties from the surrounding society can be weak during childhood and adolescence, but strengthen as the individuals mature and reach the age typical for holding a job or marrying which stakes them to a social conformity which therefore functions as a means to prevent criminal behavior. The attitudes that the younger people (Cluster 4) hold, following Laub and Sampson's theoretical approach, may in most cases change through their institutional engagement. If this reasoning is correct there should furthermore be a correlation between attitudes towards crime and criminal behavior. However, these are empirical questions for future research. We may also witness an attitudinal change, starting with young men engaged in some kind of Internet culture.

Finally, for future research we propose that more interest be placed on the population who has liberal attitudes towards white collar crime. The reason for this is that this group can be considered to be a threat towards the society by breeding general distrust, which may strain a society's social solidarity and willingness to trust others. Even though this is a small group, they are young and may continue to hold this view as they grow older, which thus would be an indication of a trend towards a more liberal attitude toward white collar crime in general.

\section{CONFLICT OF INTEREST}

The authors confirm that this article content has no conflicts of interest.

\section{ACKNOWLEDGMENTS}

None declared.

\section{REFERENCES}

Almond, P. (2008). Public Perceptions of Work-Related Fatality Cases: Reaching the Outer Limits of Populist Punitiveness'? British Journal of Criminology, 48(4), 448.

Aubert, V. (1952). White-collar crime and social structure. The American Journal of Sociology, 58(3), 263-271.

Bask, M. (2008). A longitudinal approach to social exclusion in Sweden. Umeå: Department of Sociology, Umeå universitet.

Burton, H., Karlinsky, S. S., \& Blanthorne, C. (2005). Perception Of A White-Collar Crime: Tax Evasion. American Taxation Association's Journal of Legal Tax Research, 3.

Cullen, F., Hartman, J., \& Jonson, C. (2009). Bad guys: Why the public supports punishing white-collar offenders. Crime Law and Social Change, 51(1), 31-44.

Dahlström, C. (2007). Modeller för invandrarpolitik. In M. Hjerm \& A. Peterson (Eds.), Etnicitet: Perspektiv På Samhället. Malmö: Gleerups utbildning.

Delhey, J., \& Newton, K. (2005). Predicting Cross-National Levels of Social Trust: Global Pattern or Nordic Exceptionalism? European Sociological Review, 21(4), 311-327.

Edelhertz, H. (1970). The Nature, Impact and Prosecution of White-Collar Crime. No.: ICR 70-1, 77.

Esping-Andersen, G. (1999). Social foundations of postindustrial economies. Oxford University Press Oxford.

Esping-Andersen, G. (1990). The three worlds of welfare capitalism. Cambridge: Polity.

ESS. (2004). ESS2-2004 Documentation report. The ESS Data Archive, Edition 1.0. Norwegian Social Science Data Services.

Evans, D., Cullen, F., \& Dubeck, P. (1995). Public Perceptions of Corporate Crime. In M. B. Blankenship (Ed.), Understanding Corporate Criminality. Routledge.

Gustafsson, B., \& Pedersen, P. J. (2005). Nederst vid borden i Danmark och Sverige - Relativ fattigdom bland invandrare. Ekonomisk Debatt, 33(7), 5-16.

Hirschi, T. (1969). Causes of delinquency. Berkeley: Unveristy of California Press.

Holtfreter, K., Van Slyke, S., Bratton, J., \& Gertz, M. (2008). Public perceptions of white-collar crime and punishment. Journal of Criminal Justice, 36(1), 50-60.

Jonsson, S. (1995). De andra: amerikanska kulturkrig och europeisk rasism. Stockholm: PAN/Norstedt.

Laub, J. H., \& Sampson, R. J. (2003). Shared beginnings, divergent lives: delinquent boys to age 70. Cambridge, MA: Harvard University Press.

Levi, M., \& Jones, S. (1985). Public and police perceptions of crime seriousness in England and Wales. British Journal of Criminology, 25(3), 234.

Lindgren, S.-A. (2002). Economic crime in Sweden: An essentially contested issue. Criminology and Criminal Justice, 2(4), 363-383.

Linzer, D. A., \& Lewis, J. B. (2011). poLCA: An R package for polytomous variable latent class analysis. Journal of Statistical Software, 42(10), 1-29.

National White Collar Crime Center. (2006). The 2005 National Public Survey on White Collar Crime. Retrieved from http://www.nw3c. org/. Accessed 2012, 05, 22. 
O’Connell, M., \& Whelan, A. (1996). Taking Wrongs Seriously: Public Perceptions of Crime Seriousness. British Journal of Criminology, 36(2), 299-318.

OECD. (2006). Fundamental reform of personal income tax. Paris: Organisation for Economic Co-operation and Development (OECD).

OECD. (2011). Divided we stand: why inequality keeps rising. Paris: OECD Publishing.

Rosenmerkel, S. P. (2001). Wrongfulness and harmfulness as components of seriousness of white-collar offenses. Contemporary Criminal Justice, 17(4), 308-327.

Rothstein, B., \& Uslaner, E. M. (2005). All for One: Equality, Corruption, and Social Trust. World Politics, 58(1), 41-72.

Sampson, R. J., \& Laub, J. H. (1993). Crime in the making: pathways and turning points through life. Cambridge, Mass.: Harvard University Press.

Schoepfer, A., Carmichael, S., \& Piquero, N. L. (2007). Do perceptions of punishment vary between white-collar and street crimes? Journal of Criminal Justice, 35(2), 151-163.

Schrager, L. S., \& Short Jr, J. F. (1978). Toward a sociology of organizational crime. Social problems, 407-419.

Sellin, T., \& Wolfgang, M. E. (1964). The Measurement of Delinquency. New York: Wiley.

Serajzadeh, S. H. (2008). Social Determinants of the Seriousness of Crime: An Examination of a Muslim Sample. Social Compass, 55(4), 541560 .
Sever, M., \& Roth, M. P. (2012). Public Perceptions of White-Collar Crime in Turkey and Some Comparisons with the United States. Asian Journal of Criminology, 1-23.

Shapiro, S. P. (1990). Collaring the Crime, not the Criminal: Reconsidering the Concept of White-Collar Crime. American Sociological Review, 55(3), 346-365.

Shover, N., \& Hunter, B. W. (2010). Blue-Collar, White-Collar: Crimes and Mistakes (From Offenders on Offending: Learning About Crime From Criminals, (205-227), Wim Bernasco, ed.-See NCJ-232627).

Stylianou, S. (2003). Measuring crime seriousness perceptions What have we learned and what else do we want to know. Journal of Criminal Justice, 31(1), 37-56.

Sutherland, E. H. (1940). White-Collar Criminality. American Sociological Review, 5(1), 1-12.

Sutherland, E. H. (1949). White collar crime. New York: Dryden Press.

Sutherland, E. H. (1983). White Collar Crime: The Uncut Version. Yale University Press, New Haven.

Unnever, J., Benson, M., \& Cullen, F. (2008). Public support for getting tough on corporate crime - Racial and political divides. Journal of Research in Crime and Delinquency, 45(2), 163-190.

Warr, M. (1989). What is the perceived seriousness of crimes? Criminology, 27(4), 795-822.

Wilkinson, R. G., \& Pickett, K. (2009). The spirit level: why more equal societies almost always do better. London: Allen Lane.

Received: September 07, 2012

Revised: November 02, 2012

Accepted: November 21, 2012

(C) Larsson and Alalehto; Licensee Bentham Open.

This is an open access article licensed under the terms of the Creative Commons Attribution Non-Commercial License (http://creativecommons.org/licenses/ by-nc/3.0/) which permits unrestricted, non-commercial use, distribution and reproduction in any medium, provided the work is properly cited. 